Strickland, R.A. and Vaughan, S.K. (2008). The Hierarchy of Ethical Values in Nonprofit Organizations: A Framework for an Ethical, Self-Actualized Organizational Culture. Public Integrity 10(3): 233-251 (Summer 2008). Published by M.E.Sharpe (ISSN: 1099-9922). DOI: 10.2753/PIN1099-9922100303. Available online at: http://mesharpe.com/

\title{
The Hierarchy of Ethical Values in Nonprofit Organizations: A Framework for an Ethical, Self- Actualized Organizational Culture
}

Ruth Ann Strickland and Shannon K. Vaughan

\begin{abstract}
Using Maslow's theory of human psychological development as a framework, a model based on the hierarchy of values is proposed to explain how not-for-profit organizations develop an ethical culture. As with individual values, the five levels of ethical behavior-financial competence, accountability, reciprocity, respect, integrity-are attained successively and one at a time. Thus ethical values are a foundation for achieving integrity, defined herein not only as incorruptibility but as a total commitment to the highest standards of behavior. External controls stimulate ethical behavior primarily at the lower levels; internal controls must be present to achieve an ethical organizational culture.
\end{abstract}


Inherent in the concept of ethics is a recognition of right and wrong in the decisionmaking behavior in an organization. According to Hansmann's (1980) theory of contract failure, nonprofit organizations are often the venue of choice for service delivery because they are deemed more trustworthy than business. While this is true for many reasons, numerous scandals involving nonprofit organizations have illustrated that the third sector is not immune from ethics problems. What, then, makes a nonprofit organization ethical? Studies have shown that organizational culture is one of the most important factors, if not the most important, influencing ethical behavior, especially with regard to integrity (Hendershott, Drinan, and Cross 2000). To enhance the understanding of nonprofit governance, this article proposes a model based on Maslow's hierarchy of needs for the development of an ethical culture within a not-for-profit organization.

First published in 1943, Abraham Maslow's A Theory of Human Motivation relies upon a hierarchy of needs to explain why individuals are motivated to act. Maslow sets forth five levels of needs in a firmly hierarchical structure, with the satisfaction of lower-level needs prerequisite to the attainment of the next-higher level. For example, until individuals satisfy their basic physiological needs for food, clothing, and shelter (Maslow's first level), they will be less likely to recognize opportunities to meet higher-level needs, such as love and self-esteem, or expend the effort to meet them. Self actualization-defined by Maslow as "what a man can be, he must be" (1943, 382; emphasis in original)—is the pinnacle of the hierarchy; self-fulfillment is the ultimate motivation to act, but lower-level needs that go unmet prevent its attainment.

Whereas some critics suggest that Maslow's pyramid of needs is not really a hierarchy but instead has cyclical properties, Maslow clearly theorized that the levels of needs have a scalar quality. One does not start over satisfying physiological needs once self-fulfillment is attained. Rather, because satisfaction of each level of needs is not finite-once achieved, they are not simply crossed off the list never to be faced again-scaling the hierarchy is more like climbing a mountain than completing a cycle. Climbers do not reach the summit of Mount Everest without several strategic detours back and forth to the lower levels of the mountain, but each time the detour down becomes easier and less resource-consuming. Likewise, central to the understanding of Maslow's theory of motivation is that satisfaction of lower-level needs gives individuals the slack resources to focus on a larger goal; needs that are consistently unmet divert attention from pursuing little beyond their satisfaction.

Maslow (1943) formulated an enduring and provocative theory of human motivation. Scholars have both venerated and disparaged his theory, but it is continually cited and tested more than six decades after his initial contention that individuals act based upon a hierarchy of needs. Not only does Maslow's work have mainstream appeal-with references in the popular press ranging from the Wall Street Journal and Forbes to Sports Illustrated-but his hierarchy is utilized extensively in scholarly work. Research employing the theory has been published in numerous academic journals, including Engineering Management Journal, Operations Research, the Journal of Research in Personality, and Public Administration Review. The hierarchy of needs has been applied to many different topics, including national development (Bailey 2005), business ethics (Hatwick 1986), organizational behavior (Cullen and Gotell 2002), motivation (Atwood 2004; Borkowski 2005; Halepota 2005; Janiszewski 2005; Rouse 2004), organizational resource allocation (Ivashchenko 
and Novikov 2006), information technology management (Coffee 2002; Pisello 2003), dispute resolution (Duffy and Thomson 1992), and terrorism (Schwing 2002). This body of literature gives testimony to the multidisciplinary applicability of the approach, as do the numerous introductory psychology, business management, and public administration textbooks that include discussion of the hierarchy of needs as a critical element in the study of motivation.

Although Maslow's theory is not always supported in the vast literature to which it is applied and may not apply cross-culturally, it remains an enduring framework for examining human and organizational behavior. Accordingly, the hierarchy of needs is employed herein as the basis for developing a new model for understanding the ethical behavior or lack thereof of not-for-profit organizations. As with Maslow's hierarchy of needs, it is expected that the hierarchy of ethical values in nonprofit organizations will post interesting challenges for those who seek to test it empirically, and that the challenges will either be overcome in similar fashion or provoke a stimulating debate (Latham and Pinder 2005; Lord 2002).

The discussion begins by introducing the hierarchy of ethical values. Each level is discussed in relation to Maslow's hierarchy of needs, but the model focuses on organizations and their ethical development, not on the fulfillment of individual needs within organizations. After a description of the model, internal and external controls will be discussed in relation to achieving each level in the model. Examples are provided as illustrations of the theoretical basis of the model (not as empirical tests) and serve to highlight how nonprofits exist in various stages of ethical development. Finally, the implications for the voluntary sector when nonprofits fail to seek the highest level of integrity as well as the need for further research in this area are examined.

\section{HIERARCHY OF ETHICAL VALUES IN A NONPROFIT SETTING}

To create and internalize ethical behavior, an organization must first attain certain basic ethical values. Attributes such as financial competence and accountability (Levels 1 and 2, respectively) must be attained before an organization can hope to achieve integrity (Level 5). Outside efforts to establish ethical boundaries are commendable, but the real work of creating an ethical organizational culture resides within the organization itself.

It is important to internalize an organizational culture that embraces key ethical ideals and procedures and makes them central to the organization's everyday operations (Jeavons 2005, 206). Organizations that lack an ethical compass inevitably damage their own interests as well as donor interests and may indirectly harm all others in the third sector (Schmidt 2004). The ethical hierarchy of values serves as the framework for fostering an ethical culture by encouraging (1) financial competence (managing resources and assets wisely), (2) accountability (transparency), (3) reciprocity (maintaining a mutually beneficial investment relationship with donors to meet the needs of targeted constituencies), (4) respect (incorporating the perspectives of employees, volunteers, and donors into all organizational activities), and (5) integrity (preserving incorruptibility and completeness in commitment to the mission). These values are the foundations for creating an ethical organizational culture and environment, as shown in Figure 1. 


\section{Level 1: Maintaining Competent Financial Management}

Managing assets wisely and maintaining solvency is equivalent to Maslow's concept of individual physiological needs. This value sets the organization up for success in all other areas. Financial competence promotes successful budgeting and recruitment/ retention of staff, volunteers, donors, and clients. Not-for-profits that lack the proficiency or commitment to safeguard financial resources or that use unscrupulous methods to corral resources fail to exhibit the most basic level of ethical behavior. Without achieving this most basic level, nonprofits are stymied in their efforts to articulate and pursue their mission.

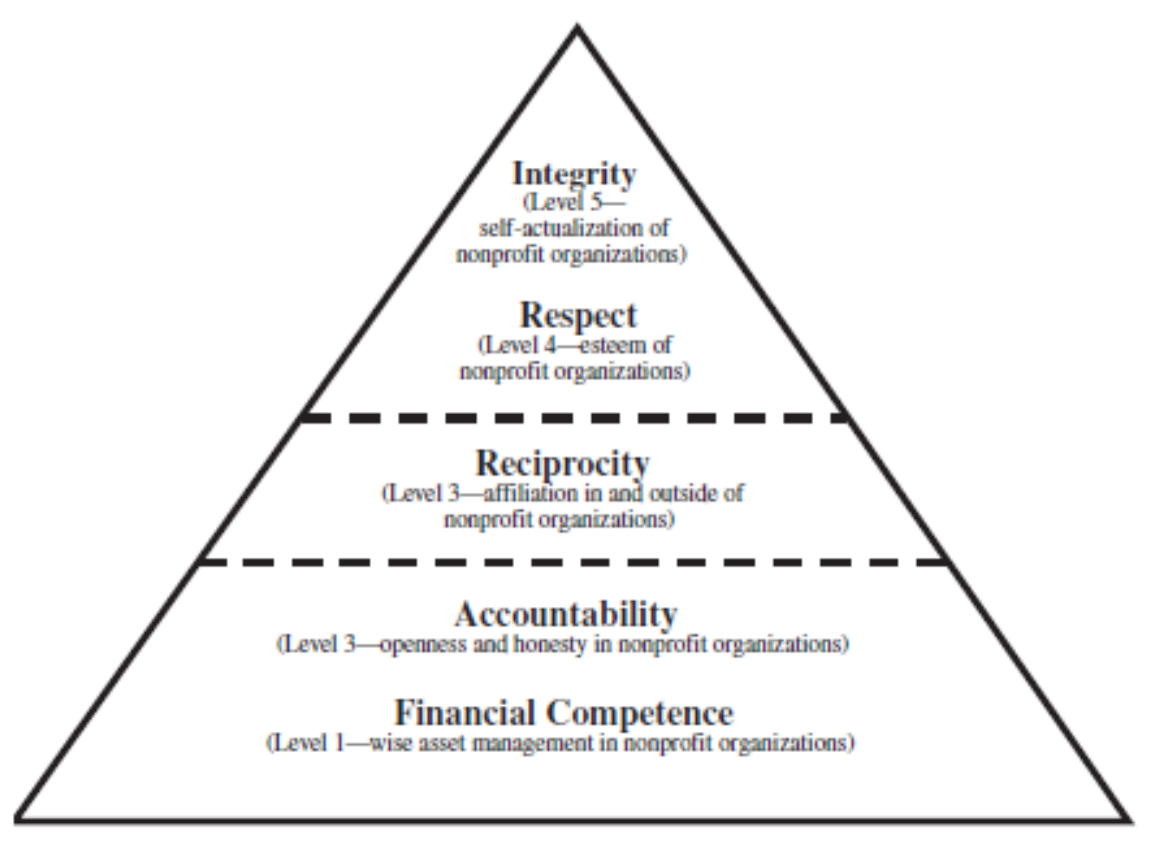

Figure 1. Hierarchy of Ethical Values for Nonprofit Organizations

As the number of not-for-profit organizations has increased dramatically in recent years, so has the competition among them for resources. Chasing financial resources, unfortunately, can lead to mission drift (Grace 2006) or vendorism (Salamon 1995). At worst, lack of fiscal competence leads to financial mismanagement, as exemplified by inaccurate financial reporting, excessive executive compensation packages, misuse of donor monies, and poor auditing procedures (Weiner 2003, 56). Lack of competent financial management carries a high price, not just in monies lost, but also for the organization's clients and for donors who put their trust in the ability of the nonprofit to achieve its stated mission. Like individuals who cannot pursue higher-level needs when they are physiologically deprived of food, water, or shelter, organizations that are financially insolvent or mismanaged lose sight of the mission. 


\section{Level 2: Establishing Accountability}

Accountability refers to the ability of nonprofit organizations to establish transparency and trust. It is equivalent to Maslow's concept of individual safety needs; accountability equates to safety in this regard because nonprofit organizations are more likely to attain security if they set up transparent procedures as well as proper oversight. When organizations follow external controls and even conform to higher standards of accountability, they are less vulnerable to scandal. In addition, accountability equates to safety in that nonprofits that establish accountability have taken steps to protect themselves from unethical behavior, thereby preventing the expenditure of resources to investigate or mitigate the consequences of such behavior.

To establish accountability, nonprofits must ask themselves who they are accountable to, for what, and how. They are held accountable internally by their own board's governance procedures; they are held accountable externally by the Internal Revenue Service and other government regulators. In addition, nonprofits also must be responsive to their stakeholders (donors, staff, members, clients, contract managers, and volunteers) as they pursue mission and maintain program effectiveness.

Finally, the general public represents the broadest category of stakeholder. Since nonprofits benefit from tax expenditures as well as direct funding by government, taxpayers and citizens have a right to monitor nonprofit activity and its value to society (Brody 2002, 473). Because nonprofits often face multiple, sometimes conflicting demands from a wide array of stakeholders, defining accountability in a way in which one size fits all is not appropriate. Still, nonprofit organizations achieve accountability only by keeping the questions of who, for what, and how foremost in their service to constituencies.

\section{Level 3: Establishing Reciprocity}

Equivalent to Maslow's concept of individual affiliation needs, reciprocity refers to the ability of nonprofit organizations to serve their constituents and donors in a manner that maximizes acceptance and trust. In practice, ethical fundraising is an example of how organizations can meet reciprocity needs. While nonprofit organizations rely on contributions to function, Grace (2006) argues that they should move beyond the beggar's tin cup and focus on match. Matching a donor's interests with a nonprofit's needs is analogous to Maslow's level of affiliation. Pursuing donors who share the organization's mission yields mutual benefits. Without reciprocity, nonprofit organizations may experience goal displacement and diverge from their mission as they pursue funds rather than partners.

By definition, not-for-profit organizations do not distribute excess revenues to third parties but retain them within the organization; therefore, they are not about making money but about providing services. As such, mission is the driving force of a nonprofit organization. It is important, therefore, that nonprofits have and adhere to a clearly articulated statement of mission and purpose (Werther and Berman 2001; Wymer, Knowles, and Gomes 2006). Board members, staff, and volunteers need a clear understanding of what the organization seeks to do, how, and why. Because the third sector depends heavily on goodwill and trust, adherence to a clear mission statement enables nonprofits to be better accountable to their supporters, members, clients, donors, and the public by making it clear how they will fulfill their philanthropic goals (Jeavons 2005, 218). 
Healthy nonprofit organizations place importance on the specific interests of the donors, volunteers, and staff associated with them, thereby employing a supplyside rationale. Supply-side functions also include social entrepreneurship, whereby commercial venues are used to foster charitable goals (Frumkin 2002; Young and Salamon 2002). Nonprofits achieve reciprocity when they recognize and celebrate the match between donor interests and their own.

\section{Level 4: Instilling the Value of Respect}

The ability to attain status and respect is important to a nonprofit organization's credibility and is equivalent to Maslow's concept of individual esteem needs. At this level of organizational culture development, the nonprofit is respected by others and, as well, has respect for itself and others. Employees feel worthwhile and appreciated. Donors, volunteers, and clients are treated as integral members of the team.

What Grace (2006) terms the donor-investor relationship embodies how nonprofits garner respect. Grace implores nonprofits to take a development rather than fundraising approach to resource recruitment. Development involves cultivating relationships with donors that induce them to view their contributions as an investment in the work being done by the nonprofit organization.

Developing relationships with donor-investors goes beyond simply asking for money. Donors are viewed as integral team members, with a specific interest in the work being done and a desire to invest in the organization as a whole, not simply to write a check. Because philanthropy is defined as "all voluntary action for the public good" (Grace 2006, 1), volunteers are celebrated as donor-investors.

\section{Level 5: Integrity and the Self-Actualized Nonprofit Organization}

The highest value in an ethical organizational culture is integrity, equivalent to Maslow's concept of individual self-actualization. Integrity is defined not only as incorruptibility, but as completeness of commitment to ethical behavior. With integrity, an organization has an internalized moral code, is able to engage in creative problem-solving, and pursues its mission to the fullest extent possible. Nonprofits that have achieved integrity assume a stewardship role in serving the public.

Aspiring to integrity and fulfilling the ethical hierarchy of needs is important if nonprofit organizations are to enjoy the full confidence of the public. Ethical governance of nonprofits is necessary to maintain their integrity. Attaining integrity relies on achieving financial competence, accountability, reciprocity, and respect. Building and maintaining social capital is essential to the ability of nonprofit organizations to mobilize support and engage in collective action (Jeavons 2005, 223). 


\section{SCALING THE HIERARCHY}

Can ethics be regulated? This framework identifies the levels of ethical development whereby nonprofit organizations reach and attain integrity. While nonprofits can be taught ethical practices, they cannot be forced to act ethically. External controls can be imposed on nonprofits to move them through financial competence and accountability, as well as to contribute to achieving reciprocity. However, only by internalizing ethical behaviors and patterns can a nonprofit attain integrity.

\section{Internal and External Controls}

Legislation, Internal Revenue Service (IRS) rules and regulations, and contract stipulations for the receipt of grant funds are all external controls on the operations of a nonprofit organization. Often these requirements are precipitated by scandals that raise awareness of a particular vulnerability. External controls may be sufficient to impose financial competence and accountability on a nonprofit, but without an internalized commitment to ethics, the organization will not move beyond Level 3-Reciprocity.

The following sections present examples of scandals that have affected nonprofit organizations. The examples should not be interpreted as empirical evidence but rather as descriptors of the model's concepts to facilitate empirical tests. They illustrate the obstacles to moving through the hierarchy of ethical values and prescriptions for overcoming them. Although the focus here is on external controls as both necessary and sufficient to achieve Levels 1 and 2, attention is also paid to the internal control mechanism that is crucial for organizations to reach the upper levels.

\section{Financial Mismanagement (Level 1)}

Like all organizations, nonprofits are not immune to scandal. Allegations of financial misconduct are the most prevalent, and ultimately the most damaging to the nonprofit organization and the voluntary sector as a whole. Charged and subsequently convicted of fraud and misuse of donor funds, Jim Bakker caused a scandal that not only brought about the demise of PTL Ministries in 1987 but contaminated other evangelical ministries by harming their reputations and their fundraising efforts (Jeavons 2005, 214).

The Ohio division of the American Cancer Society suffered stinging repercussions from the loss of $\$ 7$ million through embezzlement. Proper safeguards were not in place to prevent this-the same employee kept records, reconciled bank accounts, and had direct access to organization funds. The questions raised concerned not only why this individual had such easy access, but also why the organization had $\$ 7$ million cash on hand ("Theft from Cancer Society" 2000).

A Chronicle of Philanthropy review of 10,770 nonprofit organizational tax records from 1998 to 2001 revealed that more than 1,002 charities made $\$ 142$ million in loans to their directors, officers, or key employees (Davis 2004, 1). In 2004, People United for a Better Oakland (PUEBLO) came under fire for routinely 
making personal loans to board members and the executive director. The board chair claimed that organizations that work with poverty often have to take such "emergency measures" (Jackson and Fogarty 2005, 125). However, the loans were not made to the poor, unemployed, or disenfranchised; rather, they were made to (and sometimes not repaid by) board members, employees, and organization supporters. In addition, about $\$ 500,000$ was unaccounted for between March 2002 and March 2004 (Johnson 2004).

While staff members of nonprofits are typically underpaid relative to the market, some large nonprofit organizations often argue that it takes high salaries to attract capable executives to assist in fundraising and attract major gifts. On June 14, 2004, Carl Yeckel, former president of the Dallas-based Carl B. and Florence E. King Foundation, and Thomas Vett, the foundation's former secretary, were ordered by a jury to pay $\$ 14$ million in compensatory and punitive damages to the King Foundation. Yeckel and Vett were censured for excessive executive salaries and amassing personal charges on the foundation's credit cards (Osborn 2004).

In 2001, Hale House (a nonprofit dedicated to serving drug-addicted and abandoned babies in Harlem) faced scandal when shelter director Lorraine Hale was accused of stealing money from the organization. Hale and her husband were later sentenced to five years of probation and ordered to pay restitution for the $\$ 766,000$ they had embezzled (Saltonstall and Evans 2004, 32; "Shelter's Ex-Director" 2002). After the scandal broke, the number of donors dropped dramatically from 200,000 to 12,000; two years later, the donor base had increased to only 50,000 , one-fourth the pre-scandal size (Souccar 2004, 14).

Each of the scandals mentioned above involved issues of financial competency. Early in their development, nonprofit organizations may have more lax fiscal systems in place, due either to the administrative inexperience of the leadership or to a high degree of assumed trustworthiness within the group. Financial mismanagement is less likely to occur in organizations that internalize ethics early; for those without a strong internal orientation toward ethics, disasters like the ones described above may ensue.

\section{Accountability (Level 2)}

The prohibition against distributing profits means, in theory, that members of a board of directors have no other incentive than to act according to the best interests of the organization and its clients. Trust as a substitute for monitoring, however, is problematic when it leads to a disengaged board that is more susceptible to scandal. Transparency facilitates engagement and is an antidote to scandal.

Two members of the board of directors of the United Way of the National Capital Area (UWNCA) were removed when they pressed for open financial records; they pressed for access after being told they were not entitled to see financial statements (Strom 2003,1 ). Subsequently, a top executive stole $\$ 500,000$ from the charity and its pension fund (Hananel 2004). Later, the entire board of directors was replaced after allegedly inflating the organization's fundraising figures, understating overhead costs, and overcharging for administrative fees (Owen 2003).

The Nature Conservancy came under heavy scrutiny after the Washington Post reported that it had purchased land from Georgia-Pacific during the time that Georgia- 
Pacific's chairman sat on the Nature Conservancy board (Bobelian 2004, 4). Conservancy board members sold land to the Conservancy and then bought property from it. The leadership of the Nature Conservancy was also roundly criticized for not more carefully scrutinizing tax deductions taken by donors and for failure to make its finances more public (Stephens 2004, A01).

In 2004, a local California chapter of the American Red Cross released detailed reports on how it had spent funds after the wildfires in October 2003. The reports revealed that the nonprofit had spent 67 percent (or $\$ 3.9$ million) of its funds directly on fire victims. This stands in stark contrast to revelations from the Alpine fire in 2001 , when an audit showed that only 10 percent of funds raised went to the fire victims (Vigil 2004). A scandal ensued in which fire victims and the public wanted to know how donations were spent and how funds were managed.

\section{Achieving Levels 1 and 2}

Although organizations cannot be forced to act ethically, legal requirements can encourage achievement of Levels 1 and 2 of the hierarchy. Organizations receive (and maintain) tax-exempt status from the Internal Revenue Service (IRS) only after meeting legislatively established criteria. Therefore, nonprofits must meet financial competence and accountability requirements, such as filing IRS form 990 , to continue to benefit from tax-exempt status.

More than half of all tax-exempt organizations are classified as public charities under section 501(c)(3) of the Internal Revenue Code (Boris 1999). Public charities are subject to greater scrutiny by the IRS because they are afforded the added privilege of tax-deductibility of all contributions made to them. Therefore, the IRS has stricter criteria for recognition as a public charity and for maintaining that status (IRS 2006).

In response to the scandals involving Enron and other companies, Congress passed the Sarbanes-Oxley Act (SOX) in 2002 to deter fraud (Ostrower and Bobowick 2006). Two provisions of the act apply to all organizations, including nonprofits. Although whistleblower protection and document-retention criteria are the only mandates that apply directly to nonprofits, the act contains several other provisions that have been recognized as best practices for nonprofit governance. California's Nonprofit Integrity Act requires implementation of some of the best practices from SOX by nonprofits in that state (Jackson and Fogarty 2005).

One of the SOX best practices provisions involves auditing committees. Audit committees are a conduit between the board and the outside auditor, enhancing communication and information flow. By ensuring that the organization meets its financial responsibilities and disclosure requirements, the audit committee is positioned to identify financial irregularities before they become problematic (Owen 2003). The burden of complying with the enhanced auditing provisions of SOX depends on the provision itself. Many nonprofits already comply with some provisions, whereas others would find it very difficult to enact the provisions. More than half of the 5,115 nonprofits surveyed in the Urban Institute's National Survey of Nonprofit Governance stated that it would be somewhat or very difficult to comply with the 
provisions for establishing an audit committee. More than two-thirds said it would be difficult to comply with the requirements to rotate audit firms or lead auditors (Ostrower and Bobowick 2006).

The Sarbanes-Oxley Act also includes deterrence measures regarding conflicts of interest in publicly traded companies. Extending these provisions to nonprofit organizations would enhance accountability by facilitating greater transparency regarding board members' activities/interests. Conflict of interest may occur when a board member makes a decision out of self-interest or in the interest of only part of the organization; conflicts also can occur when the nonprofit does business with or has a financial link to a board member or a relative of the member. Internal controls regarding conflict of interest involve recusal from the decision-making process when a potential conflict of interest exists (Soltz 1997, 131), as well as development and periodic review of conflict of interest policies (Tyler and Biggs 2004, 22). According to the Urban Institute survey, 50 percent of nonprofits have a conflict of interest policy for their board members. This may be misleading, however, because while 95 percent of large organizations have such policies, only 23 percent of small ones do (Ostrower and Bobowick 2006). This suggests that resource capacity may be an issue; small organizations are more likely to be focused on issues of financial competence and accountability, with fewer slack resources to devote to concerns about conflict of interest. Therefore, organizations focused simply on meeting the external control requirements associated with Levels 1 and 2 are less likely to pursue internal controls, such as a conflict of interest policy.

Investigations by state attorneys general, auditors, or other officials also provide external controls and prompt nonprofits to adopt their own internal controls. In 2002, Ohio auditor Jim Petro found that Specialized Alternatives for Families and Youth of Ohio Inc. (SAFY) misspent state funds, using the money to buy new businesses rather than putting the funds toward the care of children. SAFY made changes in response to the audit by installing a new board of directors, new accounting software, and new policies as recommended by Petro (Bischoff 2002).

Watchdog groups also provide an external check. Some watchdog groups examine the spending practices of nonprofits, reporting the ratio of funds spent for administrative costs relative to program activities. These groups also make statements regarding the degree to which legal activities are actually ethical when practiced by nonprofits. For example, the practice of insider loans is legal, but as the example above demonstrates, this activity is not always ethical when donor funds are involved. Board members may find themselves personally liable if insider loans are not repaid (Franklin 2004). Unless a real benefit accrues to the organization as a result of the loan, private loans could jeopardize a nonprofit's tax-exempt status as well as its legitimacy with donors, thus threatening organizational security. Insider loans, if used at all, should stipulate a short-term loan at a market interest rate, with repayment closely monitored.

The American Institute of Philanthropy (2003) advocates reform measures to make boards more independent, more engaged in oversight, and more aware of the implications of their decisions. Board members should receive training on how to interpret financial reports, how to exercise oversight of budgetary matters, how to make decisions on employee and executive compensation, and how to treat staff 
and volunteers. In addition, state attorneys general are empowered to enforce board duties of care and loyalty (Brody 2002).

In order to ensure greater accountability to donors, some nonprofit advisory groups propose that nonprofits adopt a donor's bill of rights. The ten recommendations require that organizations disclose how they will use donated funds, provide the identities of the board members, and share their most recent financial statements. The bill of rights also requires nonprofits to assure donors that their donations will be used for the stated purposes for which they were given, to properly recognize donors, and to ensure that donations are handled with confidentiality. Finally, donors should be informed of whether those seeking donations are volunteers, staff, or hired marketers, and they should feel free to ask questions and receive forthright answers when making donations (Watson 2000).

The Johns Hopkins Nonprofit Listening Post Project-a March 2005 survey of 443 organizations with 207 respondents-found that 93 percent of nonprofits distribute financial statements to their boards on a quarterly basis, and 62 percent share them every month. Seventy-four percent make their financial reports available to members of the public upon request, 70 percent distribute them to donors, and 54 percent publish their statements in annual reports. Nine percent post financial reports on their organizational Web sites (Salamon 2005). These results indicate that a great many nonprofit organizations are committed to achieving accountability, by means in excess of what is required by law. Such internal commitment to ethical values bodes well for the achievement of integrity in nonprofits.

\section{Achieving Reciprocity (Level 3)}

A match between donor interests and the nonprofit's mission is critical to achieving reciprocity. As nonprofits evolve, they become more professional in orientation and outlook. It follows, therefore, that they will become more attuned to their mission and their relationship to the community as a whole. Chasing funding sources without a clear connection to mission weakens the organization, impedes reciprocity, and opens the organization to scandal.

In 2003, the Kids Wish Network-a nonprofit established to offer comfort and hope to children with terminal or life-threatening illnesses-collected \$205,255 in donations in New York through the work of professional fundraisers. After the fundraisers were paid, a mere 12 percent $(\$ 24,634)$ was retained by Kids Wish Network. In a spot check of 607 fundraising campaigns in 2002, the attorney general of New York found eight other professional fundraisers that turned over a meager 12 percent of proceeds to the charitable organization for which they were raised (Gormley 2003).

The American Institute of Philanthropy and the Better Business Bureau recommend that charities keep at least 65 percent of the monies raised by the professionals. A law enacted in California institutes more protections for consumers, making nonprofits more accountable for hiring fundraisers (Gormley 2004). For example, the Maryland Association of Nonprofits recommends that organizations work to ensure that over a period of about five years, on average every dollar spent 
on fundraising should be matched by raising at least three dollars (Causer 2004; Salmon 2004).

Many believe that making charities profitable for fundraisers erodes the principle of reciprocity - that is, that nonprofits should be responsive to donors and designated constituencies. External controls in this area are limited because the U.S. Supreme Court has consistently invalidated state laws that place numerical limits on fundraising ratios on the grounds that such limits are too restrictive of free speech and association. Most states provide ethical guidelines and publicize fundraising ratios (Bryce 2005), but achieving reciprocity ultimately requires internal control. Nonprofits that employ Grace's (2006) development approach to resource attainment are more likely to achieve reciprocity by cultivating donor-investors who support and contribute to the mission of the organization.

Although not-for-profits are prohibited from using federal grant or contract funds for lobbying activity, Congress and the Internal Revenue Service (IRS) generally support advocacy activities (including lobbying with private funds) by nonprofits. The Tax Reform Act of 1976 clarified and expanded the scope of lobbying activity permissible by 501 (c)(3) organizations, specifically by narrowing the legal definition of lobbying subject to restriction. Lobbying is differentiated from other advocacy activity because it occurs only when there is an expenditure of funds by the notforprofit organization for activities aimed specifically at influencing legislation.

Advocacy involves providing information in an effort to educate about and promote an issue or overall policy response ("Charity Lobbying" in the Public Interest, n.d.; Smucker, 1999).

The Internal Revenue Code states that a 501 (c)(3) organization "may not attempt to influence legislation as a substantial part of its activities and it may not participate at all in campaign activity for or against political candidates" (IRS n.d.). Questions have arisen, however, regarding what constitutes less than a substantial amount of time that nonprofits can legally spend in lobbying activities and at what point these organizations become too political. In 1990, in response to the confusion over how much is too much time spent lobbying, the IRS implemented the expenditure test-also known as the $\mathrm{H}$ election-as an alternative to the substantial-part rule inherent in the relevant section of the Internal Revenue Code. Nonprofits must elect to fall under the provisions of section 501(h), which prescribes specific limits on lobbying expenditures and types of lobbying, and sets some protections for organizations that commit single-year violations (Smucker 1999).

Whereas it is possible to institute external controls that facilitate reciprocity, such as reporting requirements for receipt of funds and legal restrictions on the use of funds for lobbying activity, fully achieving reciprocity requires an internal commitment. The development of donor-investors requires an internalization of an ethical commitment to serving constituents and celebrating those who contribute to the nonprofit's efforts. A match between donor interests and nonprofit mission is of paramount importance. 


\section{Achieving Respect (Level 4)}

Just as a match between donor interests and organization mission is important, a match between staff and volunteer interests is likewise essential for developing an ethical culture. Recruiting and retaining the most appropriate board members, staff, and volunteers is critical to fulfilling the nonprofit's mission. Each individual should be encouraged to engage in dialogue about his or her perceptions of the organization's mission. Tolerance of differences of opinion and cultural diversity not only make nonprofits successful, it creates a respectful organizational culture (Watson and Abzug 2005, 628).

Proper training, assignment, risk management, and motivation are crucial elements in respecting everyone associated with a nonprofit. Nonprofit organizations often fail to provide proper training for staff members who supervise volunteers, assuming that these skills come naturally. This can result in ethical and legal dilemmas. Without training, staff may be unaware of many human resource management pitfalls. Staff members who supervise volunteers should be trained on performance-appraisal, motivational, and recognition techniques (Macduff 2005, 715).

Clear job descriptions that explain the work needed, the skills required, the tasks involved, and supervisory arrangements establish boundaries for how volunteers will be used in the organization. Job descriptions enhance volunteer proficiency, and a clear outline of responsibilities prevents going into areas beyond skill level. Volunteers are more likely to feel good about their work and motivated to continue if they are equipped to be effective (McCurley 2005, 607-608). In addition, volunteers should not be asked to do work that paid staff would never be asked to do. If asked to do work that paid staff perform, volunteers should receive commensurate training (Bradner 1997, 171). Finally, organizations have an ethical obligation to provide liability insurance for volunteers (Brudney 1999, 241). By reducing volunteer fears of liability and properly training them to stay within the scope of their responsibilities, not only does the organization protect itself and its volunteers, it also better serves its clients.

Protecting staff is also important, especially staff members who seek to expose wrongdoing within the organization. Although the Sarbanes-Oxley Act prohibits retaliation against whistleblowers who provide truthful information related to the possible or actual commission of a federal offense, many nonprofits either have not formulated adequate protections for whistleblowers or are behind in implementation. A 2003 survey of 300 nonprofit CEOs revealed that 57 percent are familiar with SOX, and of these, 80 percent head nonprofits with $\$ 10$ million in revenues. Yet only 20 percent of the CEOs had changed their governance policies to comply with SOX (Sinclair 2004).

For example, Dulcy Hooper, who worked for the United Way of the National Capital Area (UWNCA), told her superiors about inconsistencies in gift reports. Not long after sharing her concerns, she was labeled "not a team player" and lost her job. She was one of many whistleblowers who were shunted aside and characterized as troublemakers. A forensic audit later conducted on UWNCA revealed years of financial mismanagement. Perhaps if the organization had listened to the natural, built-in early warning system of their gifts officer, it could have avoided a great deal of adverse publicity (Sinclair 2004). 
SOX's protections for whistleblowers provide an external control over organizational behavior, but they constitute after-the-fact enforcement as compared to the cultivation of ethical culture. Protection of individual staff members is imposed by prohibiting retaliation against whistleblowers, but respect for the same staff members is only facilitated when their comments and concerns are given legitimate concern prior to the need to blow the whistle. An ethical culture within a nonprofit organization means that employees are encouraged to blow the whistle, not merely protected once they have done so. External control, therefore, is not sufficient to embody respect and achieve Level 4 within a nonprofit organizational culture.

\section{Achieving Integrity (Level 5)}

Identifying examples of nonprofits that have achieved integrity is more challenging than identifying those that achieve financial competence, accountability, and reciprocity. Because external controls are more applicable to ensuring these types of ethical behaviors by organizations, monitoring of their successful accomplishment is more feasible. Also, as with other issues, bad behavior makes the news, whereas good behavior usually does not. Numerous watchdog groups, such as Charity Navigator and the American Institute of Philanthropy, have developed rating scales of top nonprofits, evaluating organizations based primarily on financial competence, transparency, and protection of donor interests. The nonprofits that consistently rate high on these elements are the ones most likely to achieve integrity (based on the hierarchy of ethical values proposed herein). These ratings may provide a good starting point for identifying the level of ethical culture development in nonprofit organizations. Boys \& Girls Clubs of America, the Nature Conservancy, the Mayo Clinic, and the American Red Cross are well known, and their names are brands. Branding represents a promise of organization principles, operational values, and the benefit the organization seeks to deliver to society (Wymer et al. 2006). Staff, volunteers, donors, clients, and the general public feel a sense of pride in what the organization has accomplished and, more important, trust the means by which the organization conducts its work. In addition, each of these organizations made Charity Navigator's top-ten list of the "Best Charities Everyone's Heard Of" (Charity Navigator 2006).

Achieving Level 5 means possessing a brand of integrity whereby relevant stakeholders and the general public believe that the organization has fulfilled the elements at each of the lower levels-financial competence, transparency of operations, affiliation/alliances, and genuine respect for everyone involved with the organization's work. Nonprofit organizations of integrity exhibit a stewardship approach to management and administration. According to stewardship theory, stewards place higher value and priority on collectivist rather than individualistic behaviors, that is, on cooperation rather than defection (Davis, Schoorman, and Donaldson 1997). Because the organization's performance is the primary focus, stewards are able to maximize the satisfaction of all stakeholders (including the steward's) by acting in the organization's best interests.

An ethical organizational culture in the nonprofit sector is essential to stewardship. Stewards must be vested with a high degree of trust, and therefore an internalized ethical culture is crucial to develop staff, volunteers, and board members into stewards. External controls, such as legal mandates for reporting, 
rules and regulations regarding financial management, independent watchdog groups, and so on, can only influence ethical behavior to a certain degree. Unless the individuals within the nonprofit work to ensure that the culture of the organization facilitates ethical conduct, integrity will not be achieved. For example, McCabe and Trevino $(1996,29)$ suggest that the key to curbing cheating in academia may be to "create an environment where academic dishonesty is socially unacceptable." Disapproval of cheating among peers is a chief determinant of whether students change their cheating habits between high school and college (Hendershott et al. 2000).

The importance of culture is also reflected in what Frumkin (2002) terms the expressive rationale, whereby nonprofits exist due to the desire of stakeholders to express their values and faith. The concept of stewardship is probably the most prevalent among faith-based and environmental nonprofits. For example, the National Christian Foundation-number 1 on Charity Navigator's list of "10 Best Charities Everyone's Heard Of"-defines faithful stewards as "people who understand what they hold belongs to God" (NCF 2006). Likewise, Conservation International (number 5 on the list) "believes that Earth's natural heritage must be maintained if future generations are to thrive spiritually, culturally and economically" (Cl 2006). Each of these statements implies placing individual interests secondary to the community (and organization) as a whole.

\section{CONCLUSION: IMPLICATIONS OF NOT STRIVING FOR INTEGRITY}

Simply following the letter of the law does not mean that an organization is ethical; external controls can only take an organization partway to developing an ethical culture. Many nonprofits caught up in scandal broke no laws. However, sexual misconduct by staff, excessive compensation packages for executives, drift from the organization's mission, and questionable fundraising practices all erode public confidence in the nonprofit sector. Internalization of ethics through the development of an ethical culture is necessary to ensure the integrity of the nonprofit sector so that charitable organizations can thrive.

Nonprofit organizations, like individuals, usually do not start out exhibiting the highest level of ethical behavior. Just like other organisms, nonprofits evolve, from formation through growth to maturity (Werther and Berman 2001). Likewise, nonprofits will move through the hierarchy of ethical values in a series of stages. External controls are most relevant at the first two levels of the hierarchy; laws, rules, and regulations provide useful structure and guidelines during the early years as nonprofits form their organizational culture. Reciprocity is a level of transition, as external controls become less important than internal controls in shaping the ethical behavior of the nonprofit. Respect and integrity are values achieved only through an internalized ethical culture throughout the organization.

The framework articulated in this article is intended to foster understanding of the ethical behavior or lack thereof in nonprofit organizations. The natural next step is to test the model. As mentioned, Maslow's hierarchy has been subjected to extensive study with varying results. Because the concepts built into the model are inherently subjective, empirical testing may be difficult, but it still is possible. 
This work is important; understanding what drives the ethical behavior of nonprofit organizations is especially relevant given the dramatic growth in the third sector and the increasing attention paid to ethical conduct given recent scandals across all sectors-nonprofit, private, and public.

The costs of engaging in unethical conduct far outweigh the benefits. Meeting ethical values, such as financial competency, accountability, reciprocity, and respect, empowers nonprofit organizations to fulfill their missions and to retain public trust and confidence. The long-term success of the voluntary sector will only be possible if nonprofit organizations internalize these values and become self-actualized.

\section{REFERENCES}

American Institute of Philanthropy. 2003. "Are Charity Boards Asleep at the Wheel? Nonprofit Governance Problems" (www.charitywatch.org/articles/asleep.html). Atwood, Jeffrey. 2004. "Employee Motivation of the High Achiever." SuperVision 65, no. 5:3-4.

Bailey, Charles R. 2005. Winning the Hearts and Minds: Providing the Basic Needs First. Carlisle Barracks, Pa.: U.S. Army War College.

Bischoff, Laura A. 2002. "State Audit Challenges Foster Care Agency's Costs." Dayton Daily News, October 10:B5.

Bobelian, Michael. 2004. "Following the Nonprofits." Recorder (June 1):4 (http://web. lexis-nexis.com/universe).

Boris, Elizabeth T. 1999. "Nonprofit Organizations in a Democracy: Varied Roles and Responsibilities." In Nonprofits and Government, edited by Elizabeth T. and C. Eugene Steuerle, pp. 3-29. Washington, D.C.: Urban Institute Press.

Borkowski, Nancy. 2005. "Organizational Behavior in Health Care." In Content Theories of Motivation, edited by Nancy Borkowski, pp. 113-138. Boston: Jones \& Bartlett.

Bradner, Jeanne H. 1997. "Volunteer Management." In The Nonprofit Handbook: Management, edited by Tracy Daniel Connors, pp. 162-192. New York: John Wiley.

Brody, Evelyn. 2002. "Accountability and Public Trust." In The State of Nonprofit America, edited by Lester M. Salamon, pp. 471-498. Washington, D.C.: Brookings Institution Press.

Brudney, Jeffrey L. 1999. "The Effective Use of Volunteers: Best Practices for the Public Sector.” Law \& Contemporary Problems 62 (autumn):219-254.

Bryce, Herrington J. 2005. Players in the Public Policy Process: Nonprofits as Social Capital and Agents. New York: Palgrave Macmillan.

Causer, Craig. 2004. "Special Report: Nonprofits Building Trust Through Transparency." NonProfit Times, November 1 (www.nptimes.com/Nov04/sr4.html). 
Charity Lobbying in the Public Interest. n.d. "The Basics: Nonprofit Advocacy and Lobbying" (www.clpi.org/nonprofitadvocacyandlobbying_Basics.aspy).

Charity Navigator. n.d. "10 of the Best Charities Everyone's Heard Of" (www .charitynavigator.org/index.cfm/bay/topten.detail/listid/18.htm).

Coffee, Peter. 2002. "The Hierarchy of Needs in High Tech." eWeek 19, no. 27:43. Conservation International (Cl). 2006 "Cl's Mission." http://web.conservation.org/xp/ CIWEB/about/).

Cullen, Dallas, and Lise Gotell. 2002. "From Orgasms to Organizations: Maslow, Women's Sexuality and the Gendered Foundations of the Needs Hierarchy." Gender, Work and Organization 9, no. 5:537-555.

Davis, Andrea Muirragui. 2004. "NFP Loans to Insiders Raise Legal Questions: Indiana One of 19 States to Prohibit or Limit Practice." Indianapolis Business Journal $24: 1$.

Davis, James H., F. David Schoorman, and Lex Donaldson. 1997. "Toward a Stewardship Theory of Management." Academy of Management Review 22, no. $1: 20-47$.

Duffy, Karen G., and James Thomson. 1992. "Community Mediation Centers: Humanistic Alternatives to the Court System." Journal of Humanistic Psychology 32 (spring):101-114.

Franklin, Robert. 2004. "Some Nonprofits Make Loans Close to Home; Executives, Board Members Are Recipients." Minneapolis Star Tribune, February 14:1A.

Frumkin, Peter. 2002. On Being Nonprofit: A Conceptual and Policy Primer. Cambridge, Mass.: Harvard University Press.

Gormley, Michael. 2003. "Spitzer: Charity Telemarketers Pocket \$2 For Every \$3 Raised." Associated Press State \& Local Wire [Albany, N.Y.], December 27 (http://0-web.lexis-nexis.com.wncln.wncln.org/universe).

. 2004. "Telemarketers Take Up to 90 Percent Cut in Charitable Donations." Associated Press State \& Local Wire [Albany, N.Y.], December 24 (http://0-web. lexis-nexis.com.wncln.wncln.org/universe).

Grace, Kay Sprinkel. 2006. Beyond Fundraising: New Strategies for Nonprofit Innovation and Investment. 2nd ed. Hoboken, N.J.: John Wiley.

Halepota, Hassan Ali. 2005. "Motivational Theories and Their Application in Construction." Cost Engineering 47 (March):14-18.

Hananel, Sam. 2004. "Charities Urged to Change to Restore Trust." PhillyBurbs.com (November 22).

Hansmann, Henry B. 1980. "The Role of Nonprofit Enterprise." Yale Law Journal 89 (April 1980): 835-98. 
Haruna, Peter Fuseini. 2000. "An Empirical Evaluation of Motivation and Leadership Among Career Public Administrators: The Case of Ghana." Ph.D. dissertation, University of Akron.

Hatwick, Richard E. 1986. "The Behavioral Economics of Business Ethics." Journal of Behavioral Economics 15 (spring/summer):87-101.

Hendershott, Anne, Patrick Drinan, and Megan Cross. 2000. "Toward Enhancing a Culture of Academic Integrity." NASPPA Journal 37, no. 4:587-597.

IRS (Internal Revenue Service). n.d. "Life Cycle of a Public Charity" (www.irs .gov/charities/article/0, id=12260,00.html). "Charities and Non-Profits Exemption Requirements" (www.irs.gov/charities/charitable/article/0, id=96099,00.html).

. 2006. "Life Cycle of a Public Charity" (www.irs.gov/charities/article/0,,id= 12260,00.html).

Ivashchenko, A., and D. Novikov. 2006. "Model of the Hierarchy of Needs." Automation and Remote Control 67, no. 9:1512-1517.

Jackson, Peggy M., and Toni E. Fogarty. 2005. Sarbanes-Oxley for Nonprofits: A Guide to Gaining the Competitive Advantage. Hoboken, N.J.: John Wiley.

Janiszewski, Randee. 2005. "Motivational Factors That Influence Baby Boomers Versus Generational X: Independent Insurance Agents." Ph.D. dissertation, Capella University.

Jeavons, Thomas H. 2005. "Ethical Nonprofit Management." In The Jossey-Bass Handbook of Nonprofit Leadership and Management, 2nd ed., edited by Robert D. Herman and associates, pp. 204-229. San Francisco: John Wiley.

Johnson, Chip. 2004. "Watching the Police's Watchdogs." San Francisco Chronicle, August 13:B1.

Latham, Gary P., and Craig C. Pinder. 2005. "Work Motivation Theory and Research at the Dawn of the Twenty-first Century." Annual Review of Psychology 56:485-516.

Lord, Robert L. 2002. "Traditional Motivation Theories and Older Engineers." Engineering Management Journal 14 (September):3-8.

Macduff, Nancy. 2005. "Principles of Training for Volunteers and Employees." In The Jossey-Bass Handbook of Nonprofit Leadership and Management, 2nd ed., edited by Robert D. Herman and associates, pp. 703-730. San Francisco: John Wiley.

Maslow, Abraham H. 1943. "A Theory of Human Motivation." Psychological Review 50, no. 4:370-396.

McCabe, D. L., and L. K. Trevino. 1996. "What We Know About Cheating in College." Change 28, no. 1:28-34. 
McCurley, Stephen. 2005. "Keeping the Community Involved: Recruiting and Retaining Volunteers." In The Jossey-Bass Handbook of Nonprofit Leadership and Management, 2nd ed., edited by Robert D. Herman and associates, pp. 587-622. San Francisco: John Wiley.

NCF (National Christian Foundation). 2006. "Smart Christian Giving” (www.national christian.com).

Osborn, Claire. 2004. "Two Must Pay Charity \$14 Million; Damages Are to Punish Former King Foundation Executives for Bloated Salaries, Credit Card Use." Austin American-Statesman, June 15:B1.

Ostrower, Francie, and Marla J. Bobowick. 2006. "Nonprofit Governance and the SarbanesOxley Act" (www.boardsource.org/dl.asp?document_id=473).

Owen, John R., III. 2003. "Keeping Nonprofits Clean; An Audit Committee Is Needed to Help the Board Do Its Job Correctly." Pittsburgh Post-Gazette, April 8:D2. Pisello, Tom. 2003. "Anticipating IT Needs in Pyramidal Steps." Computerworld 37, no. $34: 49$.

Rouse, Kimberly A. Gordon. 2004. "Beyond Maslow's Hierarchy of Needs: What Do People Strive For?" Performance Improvement 43, no. 10:27-31.

Salamon, Lester. 1995. Partners in Public Service. Baltimore: Johns Hopkins University Press.

_ 2005. Johns Hopkins Nonprofit Listening Post Project: Nonprofit Financial Disclosure. Communiqué No. 4 (www.jhu.edu/listeningpost/news/pdf/comm04.pdf).

Salmon, Jacqueline L. 2004. "Nonprofit Endorsements Will Expand: Maryland Group to Certify Charities Across Nation." Washington Post, June 27:C01.

Saltonstall, David, and Heidi Evans. 2004. "Hale House Chief Quits After 22 Months." New York Daily News, March 31:32.

Schmidt, Elizabeth. 2004. "How Ethical Is Your Nonprofit Organization?" (www. guidestar.org/news/features/ethics.jsp).

Schwing, Richard. 2002. "A Mental Model Proposed to Address the Sustainability and Terrorism Issues." Risk Analysis 22, no. 3:415-420.

"Shelter's Ex-Director Sentenced for Stealing." 2002. Milwaukee Journal Sentinel October 25:09A.

Sinclair, Matthew. 2004. "Nonprofit Whistleblowers Need Protection." NonProfit Times (wwwnptimes.com/Jun04/npt1.html).

Smucker, Bob. 1999. The Nonprofit Lobbying Guide. 2nd ed. Washington D.C.: Independent Sector.

Soltz, Barbara A. Burgess. 1997. "The Board of Directors." In The Nonprofit Handbook: 
Management, 2nd ed., edited by Tracy Daniel Connors, pp. 114-147. New York: John Wiley.

Souccar, Miriam Kreinan. 2004. "Nonprofit Hails New Director for Hardy Children's Charity; Will Help Hale House Rebuild After Scandal?" Crain's New York Business, April 12:14.

Stephens, Joe. 2004. "Overhaul of Nature Conservancy Urged: Report by Independent Panel Calls for Greater Openness.” Washington Post, March 31:A01.

Strom, Stephanie. 2003. "Accountability; New Equation for Charities: More Money, Less Oversight." New York Times, November 17:F1.

"Theft from Cancer Society Raises Several Questions." 2000. Columbus Dispatch, July 25:8A.

Tyler, J. Larry, and Errol L. Biggs. 2004. "Conflict of Interest: Strategies for Remaining 'Purer Than Caesar's Wife.' " Trustee 57 (March):22-26.

Vigil, Jennifer. 2004. "\$3.9 Million Spent Directly for Victims." San Diego Union-Tribune, May 2 (http://signonsandiego.com/news/fires/20040502-9999-/Im2redfunds .html/).

Watson, Charles T. 2000. "Accountability a Key Factor for Groups Soliciting Help." Ventura County Star, July 16:E06.

Watson, Mary R., and Rikki Abzug. 2005. "Finding the Ones You Want, Keeping the Ones You Find: Recruitment and Retention in Nonprofit Organizations." In The Jossey-Bass Handbook of Nonprofit Leadership and Management, 2nd ed., edited by Robert D. Herman and associates, pp. 623-659. San Francisco: John Wiley.

Weiner, Stanley. 2003. "Proposed Legislation: Its Impact on Not-For-Profit Board Governance." CPA Journal 73 (November):56 ff. (http://web.lexis-nexis.com/universe/).

Werther, William B., Jr., and Evan M. Berman. 2001. Third Sector Management: The Art of Managing Nonprofit Organizations. Washington, D.C.: Georgetown University Press.

Wymer, Walter, Jr., Patricia Knowles, and Roger Gomes. 2006. Nonprofit Marketing: Marketing Management for Charitable and Nongovernmental Organizations.

Thousand Oaks, Calif.: Sage.

Young, Dennis R., and Lester Salamon. 2002. "Commercialization, Social Ventures, and For-Profit Competition." In The State of Nonprofit America, edited by Lester M. Salamon, pp. 423-446. Washington, D.C.: Brookings Institution Press. 